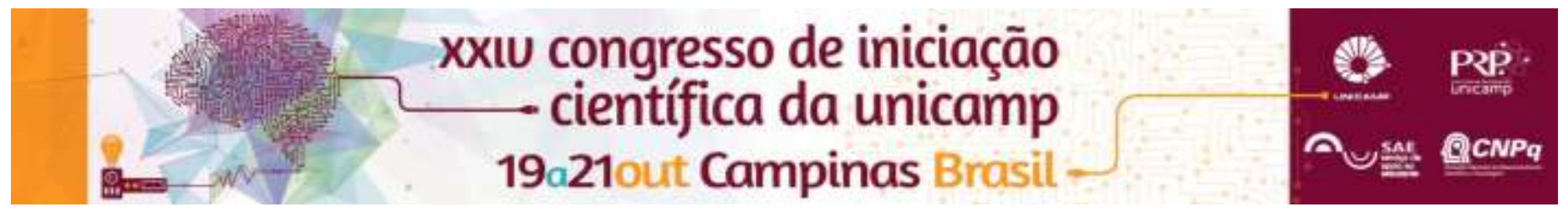

\title{
EVALUATION OF CHOLINERGIC ANTI-INFLAMMATORY PATHWAY IN THE HYPOTHALAMUS AND WHITE ADIPOSE TISSUE OF OFFSPRING MICE WITH OBESITY INDUCED BY MATERNAL CONSUMPTION OF HIGH FAT DIET
}

\section{Camilla M. Souza*, Júlia O. Sartori, Pâmela G. Lanza, Suleyma O. Costa, Santos T., Anelise C. P. Souza, Simone F. Lemes, Adriana A. Torsoni, Marciane Milanski, Marcio A. Torsoni.}

\section{Resumo}

Studies show that the high fat diet (HFD) exposure during gestation and lactation promotes obesogenic effects in offspring, such as the increase in the intracellular inflammatory signaling. Studies show that activation of $\alpha 7 n A C h R$ by nicotine suppresses the inflammation in adipose tissue and improves the insulin sensitivity in animal model of obesity. The Offspring (28 days) of mothers fed high-fat diet during pregnancy and lactation showed reduced expression of cholinergic receptor $\alpha 7 \mathrm{nAChR}$ in adipose tissue and hypothalamic. This reduction may contribute to an energy imbalance and increased predisposition to obesity.

Palavras-chave: high-fat diet, metabolic imprint, cholinergic pathway

\section{Introduction}

The potency of innate immune is controlled by cholinergic anti-inflammatory reflex. This system acts through alpha7 nicotinic receptors $(\alpha 7 n A C h R)$ and JAK2/STAT3 pathway that reduce TNF-alpha expression. $\alpha 7 n A C h R$ activation by nicotine suppresses the inflammation in adipose tissue. Aim: To evaluate the effects of maternal high fat diet (HFD) consumption on cholinergic anti-inflammatory pathway in hypothalamus and white adipose tissue (WAT) of mice offspring

\section{Results and Discussion}

Methodology:. After delivery the litter size (SC offspring, SC-O; HFD offspring, HFD-O 28 days-old) was stimulated with saline or nicotine (i.c.v. injection). Hypothalamus and WAT were collected to immunofluorescence and WB analyze. Results: $\alpha 7 n A C h R$ expression in HFD-O mice was reduced in WAT and hypothalamus by WB (Fig. 1A and 1B) and immunofluorescence (Fig. 1C and 1D) compared to SC-O mice. Nicotine ICV injection increased a7nAChR expression in SC-O mice, but did not alter a7nAChR expression in HFD-O mice ((Fig. 1A and 1B). Discussion: Reduced expression of $\alpha 7$ AchR can allow proinflammatory cytokines continue to be expressed. The diminished expression of $\alpha 7 n A C h R$ in hypothalamus can contribute to impair hormonal signaling causing the imbalance of energy homeostasis and leading to weight gain and predisposition to obesity.

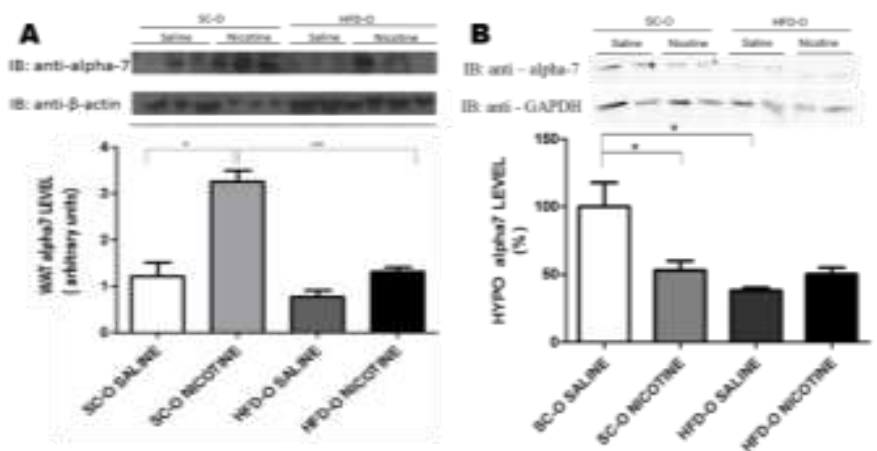

Figure 1. Western blot analysis of $\alpha 7$ AchR. A. $\alpha 7 A c h R$ in white adipose tissue B. $\alpha 7$ AchR in hypothalamus.

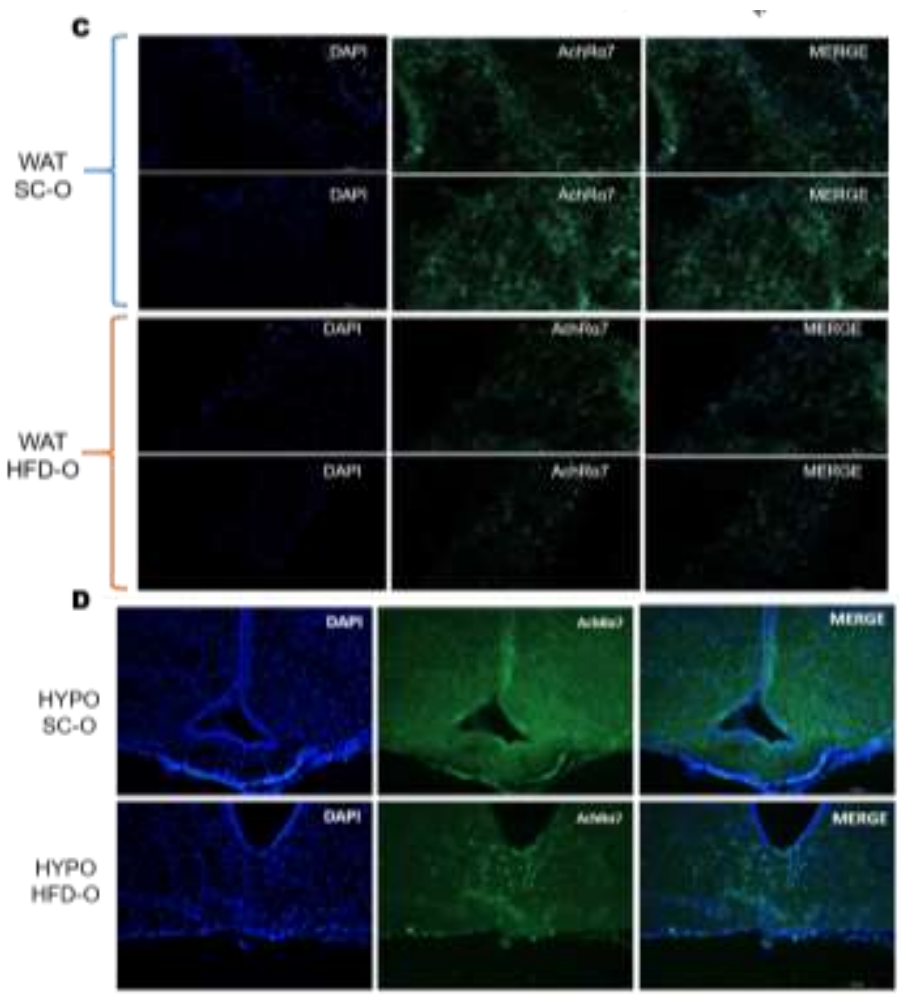

Figure 2. Immunofluorescence analysis of $\alpha 7 A c h R$ expression in white adipose tissue and hypothalamus. DAPI (blue) and a7AchR (green) in (C) adipose tissue and (D) hypothalamus of offspring from mothers fed high fat diet (HFD-O) and stand chow (SC-O) at 28 day-old. $\left({ }^{*} p<0,05,{ }^{* *} p<0,01\right)$

\section{Conclusion}

Maternal HFD consumption impairs $\alpha 7 n A C h R$ expression and modulates cholinergic anti-inflammatory signaling in hypothalamus and WAT.

\section{Congrets \\ FAPESP, PIBIC-CnPQ}

